\title{
Relationship between Sedentary Time, Physical Activity and Multiple Lifestyle Factors in Children
}

\author{
Michael P. R. Sheldrick * (1), Richard Tyler ${ }^{(\mathbb{D}}$, Kelly A. Mackintosh ${ }^{(\mathbb{D})}$ and Gareth Stratton \\ Research Centre in Applied Sports, Technology, Exercise and Medicine (A-STEM), Swansea University, \\ Swansea SA2 8PP, UK; 839039@swansea.ac.uk (R.T.); k.mackintosh@swansea.ac.uk (K.A.M.); \\ g.stratton@swansea.ac.uk (G.S.) \\ * Correspondence: 708824@swansea.ac.uk; Tel.: +44-7749-767373
}

Received: 12 December 2017; Accepted: 22 February 2018; Published: 2 March 2018

\begin{abstract}
An improved understanding of relationships between moderate-to-vigorous physical activity (MVPA), screen-time and lifestyle factors is imperative for developing interventions, yet few studies have explored such relationships simultaneously. Therefore, the study's aim was to examine the relationship between sufficient MVPA $\left(\geq 60 \mathrm{~min} \cdot \mathrm{day}^{-1}\right)$ and excessive screen-time $\left(\geq 2 \mathrm{~h} \cdot \mathrm{day}^{-1}\right)$ with lifestyle factors in children. In total, 756 children (10.4 \pm 0.6 years) completed a questionnaire, which assessed sleep duration, MVPA, homework/reading, screen-time and diet, and a 20 metre multi-stage shuttle run test to assess cardiorespiratory fitness (CRF). Body mass and stature were measured and used to calculate BMI (body mass index) for age/sex $z$-scores. Fruit and vegetable consumption and CRF were positively associated with sufficient MVPA, irrespective of sex $(p<0.05)$. Excessive screen-time was positively associated with sugary snack consumption in boys and girls, and diet soft drink intake in boys $(p<0.05)$. In addition, excessive screen-time was negatively associated with MVPA before school for both boys and girls, as well as with sleep duration and fruit and vegetable consumption for girls $(p<0.05)$. Sufficient MVPA and excessive screen-time were associated with healthy and unhealthy factors, respectively, with relationships sometimes differing by sex. Future health promoting interventions should consider targeting change in multiple lifestyle factors.
\end{abstract}

Keywords: youth; moderate-to-vigorous physical activity; screen-time; health; diet; behaviours

\section{Introduction}

Childhood obesity is a major public health concern [1], particularly in Wales, which has the highest prevalence in the United Kingdom [2], and often tracks into adulthood [3]. Associated lifetime health risks are frequently cited, such as cardiovascular disease [4], type 2 diabetes [5] and other chronic diseases [6]. There is evidence that modifiable lifestyle factors, including physical inactivity [7], poor diet [8], insufficient sleep [9] and excessive sedentary behaviour [10] are key contributors to the obesity epidemic in children and all-cause mortality. Conversely, regular physical activity [7], adequate consumption of fruit and vegetables [11] and sufficient sleep [9] are widely accepted as protective. Of these lifestyle factors, physical activity and sedentary time have been identified as the most strongly associated with obesity and health $[12,13]$. 
As well as being shown to have a robust relationship with obesity, regular moderate-to-vigorous physical activity (MVPA) is also considered to be a preventative measure for poor cardiorespiratory fitness (CRF) and several other health risk factors in children [7]. The way by which MVPA improves health is not fully understood [7], but may be partially explained by its relationship with other healthy lifestyle factors $[7,14,15]$. Indeed, MVPA is associated with healthy dietary habits, such as increased fruit and vegetable consumption [15,16], breakfast consumption [17] and a lower intake of unhealthy sugary snacks [18]. Additionally, MVPA has been associated with improved cognitive function [19] and longer sleep duration [14], however relationships with the latter are equivocal [20,21]. Despite this, MVPA levels remain low among children of all ages with less than 20 percent meeting the current UK physical activity (PA) guidelines of at least 60 minutes MVPA every day [22]. Furthermore, even children meeting the PA guidelines [23] spend a large proportion of their discretionary time in sedentary behaviours (up to 9 h daily) [10].

Whilst homework and reading have been identified as prominent sedentary behaviours amongst children [24], screen-time remains the most prevalent [10] and has been consistently associated with obesity, poor CRF, cognitive function and overall cardio metabolic health [10]. Moreover, screen-time is associated with short sleep duration [25,26], less time spent in MVPA [15,27], a poorer diet, such as lower fruit and vegetable consumption [28], greater intake of soft drinks [29] and unhealthful sugary snacks [30]. Conversely, the relationship between overall sedentary time and cardiometabolic risk markers in children is less clear $[10,31]$. Screen-time, which current public health guidelines recommend children spend no more than two hours per day engaged in [32], may therefore have a stronger link with health due to its associations with numerous unhealthy lifestyle factors [15,33].

Previous studies investigating the relationship between screen-time and other lifestyle factors have solely focused on television (TV) viewing [30,34,35], which, given the vast array of available screen-based technologies, is no longer representative of modern society. Moreover, evidence investigating activity behaviours and diet in children has mainly concentrated on screen-time rather than PA, for which data, specifically amongst British children, is limited. Whilst some studies have investigated relationships between lifestyle factors and MVPA or screen-time, these have been conducted in isolation. Assessing both relationships simultaneously will not only enable a better understanding of the associated multiple lifestyle factors, but inform future interventions.

Therefore, the present study sought to explore associations between multiple lifestyle factors and being sufficiently active $\left(\geq 60 \mathrm{~min} \cdot\right.$ day $\left.^{-1}\right)$ or engaging in excessive screen-time $\left(\geq 2 \mathrm{~h} \cdot\right.$ day $\left.^{-1}\right)$ in children.

\section{Materials and Methods}

\subsection{Participants}

Data were captured on children who participated in the Swan-Linx programme, a health and fitness initiative, which is a sister project to Sportslinx [36,37]. In total, 756 children (371 boys, 385 girls) aged $9-11$ years (10.4 \pm 0.6 years) participated in the study. Data were collected across 13 socio-demographically representative schools ((WIMD: Welsh index of multiple deprivation) [38]), within the city and county of Swansea between January and May 2015. The Swan-Linx programme has University ethical approval for its procedures and measures. Head teacher and parental consent and child assent were obtained prior to data collection.

\subsection{Instruments and Procedures}

Anthropometric measurements were obtained using standard anthropometric techniques [39], by the same trained researcher. Children had their stature and body mass measured to the nearest $0.001 \mathrm{~m}$ and $0.1 \mathrm{~kg}$, using a portable stadiometer (Seca 213 portable stadiometer, Hamburg, Germany) and electronic weighing scales (Seca 876, Hamburg, Germany), respectively. From these measures, Body Mass Index (BMI) was calculated (BMI = body mass $(\mathrm{kg}) /$ stature $^{2}(\mathrm{~m})$ ) and BMI $z$-scores were derived using the British 1990 growth reference standard [40]. The 20 metre multi-stage fitness 
test (20 MSFT) [41], which has been shown to be valid and reliable in similarly-aged children [42], was conducted by the same trained researchers using a standardised lap scoring protocol [43] to assess cardiorespiratory fitness. Both the anthropometric measurements and 20 MSFT were carried out at the indoor training centre at Swansea University.

Participants were asked to complete an online 29-item lifestyle questionnaire (CHAT: Child Health and Activity Tool) akin to the paper-based tool used in Sportlinx [44]. The CHAT questionnaire assessed time spent in MVPA, homework/reading and screen-time, as well as dietary habits, age and sleep duration. The description of screen-time included time spent watching TV, playing computer games and tablet/internet use, whereas MVPA was defined as "any activity or sport where your heart beats faster, you breathed faster and you felt warmer". Participants were asked to report time spent in each activity before ( 8 categories ranging from "no time at all" to "more than 1 hour") and after-school (10 categories ranging from "no time at all" to "more than 3 hours"). There were also questions asking the children how many days a week they engaged in excessive screen-time $\left(\geq 2 \mathrm{~h} \cdot \mathrm{day}^{-1}\right)$ and were sufficiently active $\left(\geq 60 \mathrm{~min} \cdot \mathrm{day}^{-1}\right)$. Further, participants were asked how many portions of fruit and vegetables they had consumed the previous day, whether they had breakfast, and how many days of the week they had at least one of the following: a takeaway meal, a sugary snack, a full sugar soft drink or a diet soft drink. Participants were asked to report the time they went to sleep and woke up, from which sleep duration was calculated and split into seven groups ( $<5.5 \mathrm{~h} ; 5.5-6.4 \mathrm{~h} ; 6.5-7.4 \mathrm{~h}$; 7.5-9.4 h; 9.5-11.9 h; 12-12.9 h; 13-14.5 h). Participants postcodes (i.e., zip codes) were collected to calculate a WIMD score, which considers eight domains of deprivation; employment; health; income; housing; community safety; access to services; education and the environment [38].

\subsection{Statistical Analysis}

Missing data were noted for BMI ( 8 boys (2.2\%), 29 girls (7.5\%)), CRF (20 boys (5.4\%), 22 girls $(5.9 \%))$, dietary and activity behaviours (11 boys (3\%), 12 girls $(3.1 \%)$ ) and sleep duration (16 boys $(4.3 \%), 18$ girls $(4.7 \%)$ ). Statistical analyses were completed using IBM SPSS statistics 22 (IBM SPSS Statistics Inc., Chicago, IL, USA), where significance was set at $\leq 0.05$. Whilst the normality assumption was violated, research suggests that it is not necessary when the sample size is large $(>200)[45,46]$, therefore parametric tests were deemed appropriate. Multi-collinearity diagnostics were applied to all the variables. Linear regression models, were used to examine the extent to which the lifestyle factors (BMI z-scores; CRF; screen-time, homework/reading and MVPA before and after school; fruit and vegetable consumption; breakfast consumption; full sugar soft drink intake; diet soft drink intake; sugary snack consumption; sleep duration and takeaway meal consumption) and potential confounders (i.e., WIMD and age) predicted the number of days a week in excessive screen-time and in sufficient levels of MVPA. Variables with a significant result $(p<0.10)$ were added to a multiple regression model using the backward elimination approach. Variables that were not significant $(p>0.10)$ were deleted in a stepwise manner, resulting in a model with only significant interactions $(p<0.05)$. An independent $t$-test and a $\chi^{2}$ test for the continuous and categorical variables, respectively, revealed significant differences between boys and girls and therefore regression models were conducted separately by sex. For each sex, the dependent variables were split at the median to form high and low screen-time and MVPA groups. Cut-off points of $\geq 5$ and $\geq 4$ days in sufficient MVPA for boys and girls respectively, were used to create MVPA groups. To classify screen-time groups, cut-off points of $\geq 4$ and $\geq 3$ days in excessive screen-time for boys and girls respectively were used. To help facilitate the interpretation of the different associations between the independent and dependent variables, differences between the high and low groups were tested post hoc using independent $t$-tests and $\chi^{2}$ tests for continuous and categorical variables, respectively. 


\section{Results}

Descriptive statistics for the original data set are presented in Table 1. Boys had significantly higher CRF $(p<0.01)$ compared with girls, and engaged in more screen-time before $(p<0.01)$ and afterschool $(p<0.01)$. Furthermore, boys had higher full sugar soft drink consumption $(p=0.01)$, spent more time in MVPA after school $(p=0.04)$, and consumed less fruit and vegetables $(p=0.02)$. Breakfast was consumed by $94.1 \%$ of the children ( $93.6 \%$ boys, $94.6 \%$ girls). There were no significant sex differences for the number of days a week spent in excessive screen-time [32] or in sufficient levels of MVPA [23].

Models showing significant associations between the lifestyle factors, being sufficiently active and excessive screen-time are shown in Table 2. Among boys, time spent in MVPA $(p<0.01)$ and homework/reading after school $(p=0.05)$, CRF $(p<0.01)$ and fruit and vegetable consumption $(p<0.01)$ were positively associated with being sufficiently active. Excessive screen-time was positively associated with screen-time after-school $(p<0.01)$, diet soft drink intake $(p=0.03)$ and sugary snack consumption $(p<0.01)$ and negatively associated with MVPA before school $(p=0.01)$.

For girls, being sufficiently active was positively associated with MVPA after school $(p<0.01)$, $\operatorname{CRF}(p=0.02)$ and fruit and vegetable consumption $(p<0.01)$ and negatively associated with takeaway meals $(p=0.01)$. Further, screen-time after school $(p<0.01)$ and sugary snack consumption $(p<0.01)$ were positively associated, whereas MVPA before school $(p=0.01)$, sleep duration $(p=0.03)$ and fruit and vegetable consumption ( $p=0.01$ ) were negatively associated with excessive screen-time.

Descriptive characteristics for the high vs. low groups are presented in Table 3. Post hoc analyses revealed that, irrespective of sex, children in the high PA groups had higher CRF $(p<0.01)$, consumed more fruit and vegetables $(p<0.01)$ and spent more time in MVPA before and after school $(p<0.01)$. Girls in the low PA group consumed more takeaway meals $(p<0.01)$ and had higher screen-time before school $(p=0.04)$. Regarding screen-time, girls and boys in the high group had lower CRF ( $p=0.02$ girls, $p=0.01$ boys), consumed more full sugar $(p<0.01)$ and diet soft drinks $(p=0.02$ girls, $p<0.01$ boys $)$ and consumed more sugary snacks $(p<0.01)$.

Furthermore, both sexes in the high screen-time groups consumed more takeaway meals ( $p=0.04$ girls, $p=0.01$ boys), had higher screen-time before and after school $(p<0.01)$ and spent less time in MVPA before school ( $p<0.01$ girls, $p=0.01$ boys). Moreover, girls in the high screen-time group consumed less fruit and vegetables $(p<0.01)$, while boys in this group spent less time in MVPA after school $(p=0.01)$. Although, the number of takeaway meals $(p<0.01)$ and CRF levels $(p=0.02$ girls, $p<0.01$ boys) were significantly associated with excessive screen-time in both sexes when examined separately, the associations were no longer significant in the final regression model after controlling for confounders. In addition, despite diet $(p=0.01)$ and full sugar soft drink intake $(p<0.01)$ being univariately associated with excessive screen-time in girls and boys, respectively, these associations did not remain significant after controlling for other confounders. 
Table 1. Descriptive data.

\begin{tabular}{|c|c|c|c|c|c|c|c|}
\hline \multirow[t]{2}{*}{ Characteristics } & \multicolumn{2}{|c|}{ Total Sample $(n=756)$} & \multicolumn{2}{|c|}{ Boys $(n=371)$} & \multicolumn{2}{|c|}{ Girls $(n=385)$} & \multirow[b]{2}{*}{$P$} \\
\hline & Mean (SD) & $n$ & Mean (SD) & $n$ & Mean (SD) & $n$ & \\
\hline Age (years) & $10.4(0.6)$ & 752 & $10.4(0.6)$ & 369 & $10.4(0.6)$ & 383 & 0.96 \\
\hline WIMD & $850.1(571.1)$ & 756 & $819.5(578.7)$ & 371 & $879.7(562.8)$ & 385 & 0.15 \\
\hline Height $(\mathrm{cm})$ & $142.1(7.8)$ & 731 & $141.8(7.4)$ & 366 & $142.0(8.2)$ & 365 & 0.21 \\
\hline Body mass $(\mathrm{kg})$ & $38.6(10.2)$ & 724 & $38.0(10.5)$ & 365 & $39.3(9.9)$ & 360 & 0.78 \\
\hline BMI & $18.9(3.8)$ & 723 & $18.7(3.8)$ & 365 & $19.2(3.7)$ & 358 & 0.08 \\
\hline BMI z-score & $0.6(1.3)$ & 719 & $0.6(1.3)$ & 363 & $0.6(1.3)$ & 356 & 0.06 \\
\hline CRF (No. of shuttles run) & $31.0(16.4)$ & 700 & $36.3(18.2)$ & 351 & $25.6(12.4)$ & 349 & $<0.01 *$ \\
\hline No. of days a week being sufficiently active & $4.4(2.2)$ & 733 & $4.4(2.3)$ & 360 & $4.4(2.0)$ & 373 & 0.97 \\
\hline No. of days a week in excessive screen-time & $3.7(2.4)$ & 733 & $3.9(2.4)$ & 360 & $3.6(2.4)$ & 373 & 0.14 \\
\hline No. of days a week drinking at least one full sugar soft drink & $1.9(2.1)$ & 733 & $2.1(2.3)$ & 360 & $1.7(2.0)$ & 373 & $0.01 *$ \\
\hline No. of days a week drinking at least one diet soft drink & $1.3(2.0)$ & 733 & $1.4(2.0)$ & 360 & $1.3(1.9)$ & 373 & 0.28 \\
\hline No. of fruit and vegetable portions eaten yesterday & $3.2(1.9)$ & 731 & $3.0(2.0)$ & 360 & $3.4(1.8)$ & 371 & $0.02 *$ \\
\hline No. of days a week eating at least one sugary snack & $3.2(1.9)$ & 733 & $3.2(2.2)$ & 360 & $3.2(2.0)$ & 373 & 0.71 \\
\hline No. of days a week eating at least one takeaway meal & $1.0(1.3)$ & 733 & $1.0(1.4)$ & 360 & $1.0(1.3)$ & 373 & 0.53 \\
\hline MVPA before school (min) & $14.2(15.5)$ & 733 & $14.6(15.7)$ & 360 & $14.0(15.2)$ & 733 & 0.16 \\
\hline MVPA after school (min) & $54.1(55.5)$ & 732 & $60.3(60.7)$ & 360 & $48.0(49.2)$ & 732 & $0.04 *$ \\
\hline Homework/reading before school (min) & $10.4(13.8)$ & 733 & $10.4(13.8)$ & 360 & $10.0(13.8)$ & 373 & 1.00 \\
\hline Homework/reading after school (min) & $17.7(25.8)$ & 732 & $16.2(25.9)$ & 360 & $19.0(25.6)$ & 372 & 0.12 \\
\hline Screen-time before school (min) & $14.0(18.7)$ & 733 & $17.1(20.2)$ & 360 & $11.0(16.6)$ & 373 & $<0.01$ * \\
\hline Screen-time after school (min) & $45.1(52.1)$ & 732 & $55.7(59.0)$ & 360 & $35.0(41.9)$ & 372 & $<0.01 *$ \\
\hline Sleep duration $(h)$ & $9.8(1.3)$ & 723 & $9.8(1.5)$ & 354 & $9.9(1.2)$ & 367 & 0.35 \\
\hline
\end{tabular}

$p$-Values are based on significance level from the independent $t$-test for continuous variables (non-italics) or the chi-squared test for categorical variables (italics). ${ }^{*}$ Relationship is significant. BMI: body mass index; CRF: cardio-respiratory fitness; MVPA: moderate-to-vigorous intensity physical activity; WIMD: welsh index of multiple deprivation. 
Table 2. Multiple regression models conducted separately by sex.

\begin{tabular}{|c|c|c|c|c|c|c|c|}
\hline \multirow{2}{*}{ Model } & \multirow{2}{*}{ Predictors } & \multicolumn{3}{|c|}{ Boys $(n=371)$} & \multicolumn{3}{|c|}{ Girls $(n=385)$} \\
\hline & & B (SE) & $\beta$ & $P$ & B (SE) & $\beta$ & $P$ \\
\hline \multirow{7}{*}{ No. of days being sufficiently active } & MVPA before school (min) & - & - & - & $0.01(0.01)$ & 0.09 & 0.06 \\
\hline & MVPA after school (min) & $0.01(0.00)$ & 0.38 & $<0.01 *$ & $0.01(0.00)$ & 0.35 & $<0.01 *$ \\
\hline & Homework/reading after school (min) & $0.01(0.00)$ & 0.09 & $0.05 *$ & - & - & - \\
\hline & CRF (No. of shuttles run) & $0.03(0.01)$ & 0.20 & $<0.01$ * & $0.02(0.01)$ & 0.11 & $0.02 *$ \\
\hline & No. of days a week eating at least one takeaway meal & - & - & - & $-0.20(0.07)$ & -0.13 & $0.01 *$ \\
\hline & No. of fruit and vegetable portions eaten yesterday & $0.27(0.05)$ & 0.25 & $<0.01^{*}$ & $0.27(0.06)$ & 0.24 & $<0.01$ * \\
\hline & $R^{2}$ (adjusted $R^{2}$ ) & \multicolumn{3}{|c|}{$0.35(0.34)$} & \multicolumn{3}{|c|}{$0.30(0.29)$} \\
\hline \multirow{11}{*}{ No. of days in excessive screen-time } & MVPA before school (min) & $-0.02(0.01)$ & -0.12 & $0.01 *$ & $-0.02(0.01)$ & -0.13 & $0.01 *$ \\
\hline & Homework/reading before school ( $\min )$ & $-0.01(0.01)$ & -0.08 & 0.08 & - & - & - \\
\hline & Screen-time before school (min) & $0.03(0.01)$ & 0.22 & $<0.01 *$ & $0.03(0.01)$ & 0.18 & $<0.01$ * \\
\hline & Screen-time after school (min) & $0.02(0.00)$ & 0.35 & $<0.01 *$ & $0.02(0.00)$ & 0.27 & $<0.01 *$ \\
\hline & No. of fruit and vegetable portions eaten yesterday & - & - & - & $-0.17(0.07)$ & -0.12 & $0.01 *$ \\
\hline & No. of days a week drinking at least one diet drink & $0.11(0.05)$ & 0.09 & $0.03 *$ & - & - & - \\
\hline & No. of days a week drinking at least one full sugar soft drink & - & - & - & $0.12(0.60)$ & 0.10 & $0.05 *$ \\
\hline & No. of days a week eating at least one sugary snack & $0.17(0.05)$ & 0.16 & $<0.01$ * & $0.18(0.06)$ & 0.15 & $<0.01$ * \\
\hline & Age & - & - & - & $0.37(0.19)$ & 0.09 & $0.05 *$ \\
\hline & Sleep duration & - & - & - & $-0.36(0.17)$ & -0.10 & $0.03 *$ \\
\hline & $R^{2}$ (adjusted $R^{2}$ ) & \multicolumn{3}{|c|}{$0.41(0.40)$} & \multicolumn{3}{|c|}{$0.33(0.32)$} \\
\hline
\end{tabular}

CRF: Cardio-respiratory fitness; MVPA: moderate-to-vigorous intensity physical activity. ${ }^{*}$ Relationship is significant. 
Table 3. Descriptive statistics for the high and low screen-time and MVPA groups.

\begin{tabular}{|c|c|c|c|c|c|c|c|c|c|c|c|c|}
\hline \multirow{2}{*}{ Characteristics } & \multicolumn{5}{|c|}{ Boys $(n=371)$} & \multicolumn{7}{|c|}{ Girls $(n=386)$} \\
\hline & $\begin{array}{c}\text { Low MVPA } \\
\quad(n=165)\end{array}$ & $\begin{array}{c}\text { High MVPA } \\
(n=195)\end{array}$ & & $\begin{array}{c}\text { Low Screen-Time } \\
\quad(n=187)\end{array}$ & $\begin{array}{l}\text { High Screen-Time } \\
\quad(n=173)\end{array}$ & & $\begin{array}{c}\text { Low MVPA } \\
\quad(n=137)\end{array}$ & $\begin{array}{c}\text { High MVPA } \\
(n=236)\end{array}$ & & $\begin{array}{c}\text { Low Screen-Time } \\
(n=141)\end{array}$ & $\begin{array}{l}\text { High Screen-Time } \\
\quad(n=232)\end{array}$ & \\
\hline & Mean (SD) & Mean (SD) & $P$ & Mean (SD) & Mean (SD) & $P$ & Mean (SD) & Mean (SD) & $P$ & Mean (SD) & Mean (SD) & $P$ \\
\hline Age (years) & $10.4(0.6)$ & $10.4(0.6)$ & 0.16 & $10.4(0.6)$ & $10.4(0.6)$ & 0.27 & $10.3(0.6)$ & $10.5(0.6)$ & $<0.01^{*}$ & $10.3(0.6)$ & $10.5(0.6)$ & 0.08 \\
\hline WIMD & $799.0(578.9)$ & 834.9 (580.4) & 0.56 & 917.1 (576.6) & 771.9 (564.4) & $<0.01 *$ & $872.3(546.5)$ & $885.8(574.2)$ & 0.82 & $916.0(566.4)$ & $859.4(561.8)$ & 0.35 \\
\hline Height $(\mathrm{cm})$ & $141.1(7.8)$ & $142.4(7.2)$ & 0.10 & $141.7(6.9)$ & $141.9(8.1)$ & 0.84 & $140.8(8.3)$ & $143.4(8.1)$ & $<0.01 *$ & $141.6(8.2)$ & $142.9(8.2)$ & 0.16 \\
\hline Body mass (kg) & $37.8(11.0)$ & $38.4(10.3)$ & 0.57 & $37.9(9.4)$ & $38.4(11.8)$ & 0.68 & $38.3(10.5)$ & $40.1(9.7)$ & 0.09 & $38.5(9.3)$ & $40.0(10.0)$ & 0.16 \\
\hline BMI & $18.7(3.8)$ & $18.7(3.8)$ & 0.93 & $18.7(3.5)$ & $18.8(4.1)$ & 0.79 & $19.2(4.2)$ & $19.3(3.5)$ & 0.65 & $19.0(3.5)$ & $19.4(3.9)$ & 0.29 \\
\hline BMI $z$-score & $0.6(1.4)$ & $0.6(1.3)$ & 0.98 & $0.7(1.2)$ & $0.6(1.4)$ & 0.58 & $0.5(1.5)$ & $0.6(1.1)$ & 0.40 & $0.5(1.2)$ & $0.6(1.3)$ & 0.53 \\
\hline $\begin{array}{l}\text { CRF (No. of } \\
\text { shuttles run) }\end{array}$ & 30.1 (14.8) & $41.1(19.4)$ & $<0.01 *$ & $38.7(18.7)$ & 33.2 (17.4) & $0.01 *$ & $22.5(10.4)$ & $27.2(13.2)$ & $<0.01 *$ & $27.6(13.7)$ & $24.1(11.3)$ & $0.02 *$ \\
\hline $\begin{array}{l}\text { No. of days a week } \\
\text { being sufficiently } \\
\text { active }\end{array}$ & $2.3(1.3)$ & $6.3(0.9)$ & $<0.01^{*}$ & $4.6(2.2)$ & $4.3(2.4)$ & 0.25 & $2.2(0.9)$ & $5.7(1.2)$ & $<0.01 *$ & $4.5(2.1)$ & $4.4(2.0)$ & 0.44 \\
\hline $\begin{array}{l}\text { No. of days a week in } \\
\text { excessive screen-time }\end{array}$ & $4.1(2.5)$ & $3.7(2.4)$ & 0.10 & $1.8(1.0)$ & $6.2(1.1)$ & $<0.01 *$ & $3.7(2.5)$ & $3.5(2.3)$ & 0.40 & $1.1(0.8)$ & $5.1(1.6)$ & $<0.01$ * \\
\hline $\begin{array}{l}\text { No. of days a week } \\
\text { drinking at least one } \\
\text { full sugar soft drink }\end{array}$ & $2.1(2.2)$ & $2.1(2.3)$ & 0.93 & $1.5(1.9)$ & $2.8(2.5)$ & $<0.01$ * & $1.9(2.0)$ & $1.6(2.0)$ & 0.17 & $1.2(1.6)$ & $2.0(2.2)$ & $<0.01$ * \\
\hline $\begin{array}{l}\text { No. of days a week } \\
\text { drinking at least one } \\
\text { diet soft drink }\end{array}$ & $1.4(2.0)$ & $1.4(2.1)$ & 0.93 & $1.1(1.6)$ & $1.8(2.4)$ & $<0.01 *$ & $1.3(1.9)$ & $1.2(1.9)$ & 0.69 & $1.0(1.6)$ & $1.4(2.0)$ & $0.02 *$ \\
\hline $\begin{array}{l}\text { No. of fruit and } \\
\text { vegetable portions } \\
\text { eaten yesterday }\end{array}$ & $2.3(1.8)$ & $3.7(2.0)$ & $<0.01$ * & $3.2(2.0)$ & $2.8(2.1)$ & 0.06 & $2.7(1.6)$ & $3.8(1.8)$ & $<0.01$ * & $3.8(1.8)$ & $3.1(1.7)$ & $<0.01$ * \\
\hline $\begin{array}{l}\text { No. of days a week } \\
\text { eating at least one } \\
\text { sugary snack }\end{array}$ & $3.2(2.3)$ & $3.3(2.2)$ & 0.56 & $2.4(1.8)$ & $4.1(2.4)$ & $<0.01$ * & $3.2(2.0)$ & $3.2(2.1)$ & 0.93 & $2.5(1.7)$ & $3.6(2.1)$ & $<0.01$ * \\
\hline $\begin{array}{l}\text { No. of days a week } \\
\text { eating at least one } \\
\text { takeaway meal }\end{array}$ & $1.0(1.4)$ & $1.1(1.3)$ & 0.51 & $0.9(1.1)$ & $1.2(1.6)$ & $0.01 *$ & $1.2(1.5)$ & $0.8(1.2)$ & $<0.01 *$ & $0.8(1.3)$ & $1.1(1.3)$ & 0.04 * \\
\hline $\begin{array}{l}\text { MVPA before } \\
\text { school (min) }\end{array}$ & $9.6(12.5)$ & $18.9(16.9)$ & $<0.01 *$ & $17.7(17.4)$ & $11.3(13.1)$ & $0.01 *$ & $10.7(14.5)$ & $15.4(15.1)$ & $<0.01$ * & $17.9(16.7)$ & $11.1(13.3)$ & $<0.01$ * \\
\hline
\end{tabular}


Table 3. Cont

\begin{tabular}{|c|c|c|c|c|c|c|c|c|c|c|c|c|}
\hline \multirow{2}{*}{ Characteristics } & \multicolumn{5}{|c|}{ Boys $(n=371)$} & \multicolumn{7}{|c|}{ Girls $(n=386)$} \\
\hline & $\begin{array}{c}\text { Low MVPA } \\
(n=165)\end{array}$ & $\begin{array}{c}\text { High MVPA } \\
(n=195)\end{array}$ & & $\begin{array}{c}\text { Low Screen-Time } \\
(n=187)\end{array}$ & $\begin{array}{c}\text { High Screen-Time } \\
\quad(n=173)\end{array}$ & & $\begin{array}{c}\text { Low MVPA } \\
(n=137)\end{array}$ & $\begin{array}{l}\text { High MVPA } \\
(n=236)\end{array}$ & & $\begin{array}{c}\text { Low Screen-Time } \\
\quad(n=141)\end{array}$ & $\begin{array}{l}\text { High Screen-Time } \\
\quad(n=232)\end{array}$ & \\
\hline $\begin{array}{l}\text { MVPA after } \\
\text { school (min) }\end{array}$ & $32.2(42.7)$ & $84.0(63.5)$ & $<0.01 *$ & $69.8(62.2)$ & $49.9(57.4)$ & $0.01 *$ & $25.4(31.2)$ & $61.5(53.0)$ & $<0.01 *$ & $55.6(50.2)$ & $43.7(48.3)$ & 0.24 \\
\hline $\begin{array}{l}\text { Homework/reading } \\
\text { before school (min) }\end{array}$ & $8.4(11.9)$ & $12.2(14.9)$ & 0.08 & $11.6(14.5)$ & $9.2(12.9)$ & 0.35 & $8.8(12.6)$ & $11.3(14.4)$ & 0.70 & $12.5(14.6)$ & $9.1(13.2)$ & 0.20 \\
\hline $\begin{array}{l}\text { Homework/reading } \\
\text { after school (min) }\end{array}$ & $12.7(20.7)$ & $19.1(29.4)$ & 0.25 & $16.5(23.4)$ & $15.9(28.4)$ & 0.81 & 14.7 (16.9) & $21.8(29.3)$ & 0.39 & $19.4(20.5)$ & $19.1(28.3)$ & 0.53 \\
\hline $\begin{array}{l}\text { Screen-time before } \\
\text { school (min) }\end{array}$ & $18.8(21.0)$ & $15.7(19.4)$ & 0.72 & $9.9(13.9)$ & $24.8(22.9)$ & $<0.01 *$ & $14.3(18.9)$ & $9.1(15.0)$ & $0.04 *$ & $5.4(11.6)$ & $14.4(18.4)$ & $<0.01$ * \\
\hline $\begin{array}{l}\text { Screen-time after } \\
\text { school (min) }\end{array}$ & $61.2(62.1)$ & $51.0(56.0)$ & 0.21 & $28.9(38.1)$ & $84.6(63.9)$ & $<0.01 *$ & $41.5(47.0)$ & $31.1(38.4)$ & 0.29 & $17.0(26.5)$ & $45.9(45.9)$ & $<0.01$ * \\
\hline Sleep duration (h) & $9.7(1.5)$ & $9.8(1.4)$ & 0.55 & $9.9(1.3)$ & $9.6(1.6)$ & 0.11 & $9.9(1.2)$ & $10.0(1.2)$ & 0.97 & $10.1(1.2)$ & $9.8(1.2)$ & 0.12 \\
\hline
\end{tabular}

$p$-Values are based on significance level from the independent $t$-test for continuous variables (non-italics) or the chi-squared test for categorical variables (italics). ${ }^{*}$ Relationship is significant. BMI: body mass index; CRF: Cardio-respiratory fitness; MVPA: moderate-to-vigorous intensity physical activity; WIMD: welsh index of multiple deprivation. The cut-off value for MVPA was $\geq 5$ and $\geq 4$ days in sufficient MVPA for boys and girls respectively. The cut-off value for screen time was $\geq 4$ and $\geq 3$ days in excessive screen-time for boys and girls respectively. 


\section{Discussion}

The present study aimed to explore associations between MVPA, sedentary time and multiple lifestyle factors in 9-11 years old children. Of note, there was no inverse relationship between days spent in excessive screen-time and sufficient levels of MVPA or vice versa. Although studies have reported an inverse relationship between sedentary time and MVPA [47], there is insufficient evidence to assume a reciprocal relationship [47]. Whilst both behaviours may directly compete with each other during a specific time period (e.g., after school) [47], the same may not be true for an entire day or across a week [48]. Further, similar to previous research [15,25,29,49], excessive screen-time was associated with unhealthy factors, which were different to those inversely related to sufficient levels of MVPA. Indeed, available evidence suggests that they are two separate entities [9], which are independently associated with health [10].

While boys were more active than girls after school, both were sufficiently active for the same number of days a week. Consistent with a recent review [7], sufficient levels of MVPA were positively related to CRF independent of sex. Aside from low CRF, low fruit and vegetable intake is another weight-related risk factor [11]. In agreement with previous research $[15,16,50]$, strong positive associations between fruit and vegetable consumption and sufficient levels of MVPA were observed in both sexes. Conversely, Pereira et al. [51] found a negative relationship, whereas Vissers et al. [52] and Jago et al. [53] found a positive relationship in boys and girls, respectively. The equivocal findings may, in part, be a result of different methodologies and sample characteristics; Pereira et al. [51] found active children engaged in more screen-time, and studies have suggested a negative relationship between screen-time and fruit and vegetable consumption [29,49]; in contrast to the present study, Vissers et al. [52] found MVPA to be significantly higher in boys and Jago et al. [53] recorded dietary and PA measures 12 months apart.

Sleep duration is an important component of health in children [9] and has been associated with MVPA, however evidence is scarce and contradictory. In our study, sufficient levels of MVPA were not associated with sleep duration. On the contrary, Stone et al. [14] found MVPA to be higher among children with $>10$ h of sleep per night compared with those who slept $<9 \mathrm{~h}$ per night. However, it is noteworthy that Stone et al. [14] used parental report to assess sleep duration, which is thought to have questionable reliability, as parents tend to overestimate sleep duration [54,55]. Although children can also overestimate sleep duration [56], our finding that sleep duration was not associated with MVPA is in agreement with several studies that measured sleep duration objectively [21,57]. In children of this age, sleep duration may be more susceptible to environmental factors, such as social activities or school arrangements than the actual need for sleep [57], which may explain why MVPA was not directly associated. However, MVPA has been associated with better sleep efficiency $[57,58]$ and shorter sleep latency [57] and is therefore considered beneficial for sleep in children.

Converse to a systematic review [59], this study did not find an association between BMI and sufficient levels of MVPA irrespective of sex. There was a large amount of data missing for BMI in girls $(7.5 \%)$; although the weight status of these girls is unknown, it is possible that they were overweight or obese. The extent to which this biased results is unclear, however it may provide a reason for why there was no association between BMI and MVPA in girls. Further, this relationship may be more related to the intensity of PA as opposed to total PA [60]; therefore the aggregation of moderate (MPA) and vigorous (VPA) physical activity may, in part, explain this discrepancy.

The lack of association between excessive screen-time and BMI- $z$ scores in the present study, may have been due to the low prevalence of reported screen-time in the sample. On average, children engaged in $\geq 2$ hours of screen-time for only 3.7 days a week, compared with the average of 3 hours per day reported in studies observing a relationship between screen-time and adiposity in children [12,61]. Therefore, perhaps only higher durations of screen-time are associated with adiposity in children [10]. Although the underpinning mechanisms behind the relationship between screen-time and adiposity are not completely understood [10], the association between screen-time and elements of a less healthy diet is believed to be a contributing factor [29]. Sugary snack consumption was positively associated 
with excessive screen-time in this study, in agreement with previous research [28,29,49]. As sugary snack consumption has been shown to increase overall caloric intake [8], it may be an important factor in the screen-time and obesity/overweight relationship. Screen-time may influence sugary snack consumption in children in several ways, through exposure to advertisements for sugary snacks on TV or online [62], reduced sensitivity to satiety cues and messages imbedded in TV programmes [63]. Interestingly, diet soft drinks are the most highly advertised product on TV [62], and since boys watch more TV $[33,64]$, they are more exposed to these advertisements which may explain the positive relationship between diet soft drinks and excessive screen-time in boys.

For girls only, low fruit and vegetable consumption was associated with screen time, consistent with a recent review by Pearson and Biddle [49]. It is not clear why the relationship only exists in girls, but it may be partially explained by the positive but non-significant relationship between sufficient levels of MVPA and excessive screen-time in boys $(p=0.08)$. Similarly, others have also found high levels of MVPA and screen-time to co-exist in boys $[65,66]$. Therefore, fruit and vegetable consumption may be higher among boys who engage in excessive screen time as they are also achieving sufficient levels of MVPA, since a positive relationship exists between the latter and fruit and vegetable consumption.

In contrast to previous research $[25,26]$, we observed a negative relationship between screen-time and sleep duration only in girls. The reason for this sex difference is not clear, but mobile phone and MP3 player use is higher among girls, whereas watching TV and video gaming is higher among boys [64]. As mobile phones and MP3 players are easier to hide from parents in bed [67], it could be postulated that the more frequent use of these devices by girls before bedtime could reduce sleep time.

The negative relationship observed between MVPA before school and excessive screen-time may reflect findings from Gorely et al. [68] whereby adolescents who commuted to school via motorised transport were more likely to spend their discretionary time watching screens. Since active travel is considered the main source of MVPA before school [36], it is possible that children who engaged in excessive screen-time commuted to and from school via motorised transport. However, since few studies have investigated associations between active travel to school and screen-time in children to date, more research is needed to confirm the potential influence of active travel on habitual screen-time.

We found positive associations between MVPA and screen-time after-school and meeting and exceeding their respective recommendations, respectively, which supports the hypothesis that the after-school period is key for the accumulation of MVPA and screen-time [36]. Indeed, Atkin et al. [24] revealed that time spent in both screen-time and MVPA during the after-school period (15:30-18:30) accounted for approximately $30 \%$ and $40 \%$, respectively, of daily totals. Further, Olds et al. [27] found that during this period the greatest variation in MVPA levels occurred between high active and low active children.

Although screen-time and MVPA are the most prominent behaviours during the after-school period [24,69], productive sedentary behaviours, such as homework and reading, also occur and are thought to directly compete with MVPA [70]. However, in the present study, there was a positive relationship between homework/reading after school and sufficient levels of MVPA in boys, similar to data reported in adolescents [71]. In accord with Booth et al. [19], this suggests that there is time for both MVPA and homework and reading throughout the day and provides support for the beneficial influence of MVPA on school endeavours in boys at least. In contrast to most types of screen-based sedentary behaviours, these productive sedentary behaviours are considered essential for a child's education and development [9].

The present study has numerous strengths. Firstly, to the authors' knowledge, it is the first study to investigate the associations of both sufficient levels of MVPA and excessive screen-time with multiple lifestyle factors in children within the same sample. The integration of new types of technology for assessing screen-time advances previous research, which focused solely on television viewing $[30,34,35]$. This is important as screen-time is constantly changing due to technological advances, and multifunctional devices such as tablets, smartphones and computers are now frequently 
used by children [64]. Moreover, children regularly engage in two or more forms of screen viewing simultaneously [72]. Therefore, children can over-report screen-time when responding to certain self-report questions, however we were able to address this with our excessive screen-time question. Further, the sample was socio-demographically representative of the area and the detailed information collected enabled us to control for a number of variables. Also, while there is sufficient research investigating associations between diet and MVPA in adults [73] and adolescents [74], there is a paucity of research among children. In addition, the present study established a number of sex differences in relationships, uncommon in the literature. These may be a function of measurement issues, but equally, they may just be sample dependent, differing by cultural environments, age or country of study.

Nonetheless, certain limitations should be acknowledged. Given the cross-sectional nature of the study, it is not possible to infer causal relationships and future research should clarify such complex relationships by examining longitudinal associations. In addition, the time-specific measures used to assess diet, MVPA, screen-time and sleep duration may not have captured habitual behaviour. Future studies should seek to assess diet [28,52] and screen-time [75] using 7 day diary/logs and similarly PA [13] and sleep duration [76] for 7 days by accelerometer. Measuring PA using an accelerometer also allows researchers to quantify intensity, which the questionnaire did not allow as it primarily focused on the frequency and duration of PA. Indeed, MPA and VPA were aggregated, and VPA is more consistently associated with health [7]. Moreover, the comparably low prevalence of excessive screen-time found in the sample may be due, at least in part, to social desirability, inherent in self-reporting [75]. Unfortunately, as the screen-time measure is an aggregate of three behaviours, we could not examine TV viewing, playing computer games and tablet/internet use separately. There is evidence to suggest that internet use for productive purposes, is not related to poor lifestyle habits in adolescents [77]. Even internet use for gaming may have less of an impact on poor lifestyle habits, such as snacking than TV viewing, particularly in boys [78]. Direct comparisons between this cross-sectional study and others are limited by the different study designs and methodologies used to assess behaviours. Whilst, previous studies examining multiple lifestyle factors have used approaches such as cluster and co-occurrence analyses [51,79], this is one of the few to explore the independent associations between MVPA, screen-time and several other lifestyle factors, while simultaneously controlling for potential confounders. The approach utilized in the present study enabled the identification of several important lifestyle factors, which could be beneficially influenced through implementing interventions designed to change MVPA and screen-time. As such, the study is of significant public health interest.

\section{Conclusions}

Taken together, the present study enables researchers to gain a better understanding of other lifestyle factors associated with MVPA and screen-time in children. Specifically, both healthy and unhealthy lifestyle factors, differing by sex, were associated with sufficient levels of MVPA and excessive screen-time respectively. Future interventions seeking to promote health behaviours, should target change in multiple lifestyle factors, with sex-specific strategies. Further, the home environment is recognised to have a large influence on lifestyle factors in children, particularly on sedentary time and MVPA [80]. Therefore, research exploring lifestyle correlates of MVPA and sedentary time within this environment is needed.

Acknowledgments: The authors wish to thank the schools, the children and their parents for their participation in the Swan-Linx programme. The authors would also like to acknowledge everyone who helped with data collection. Michael Sheldrick is supported by a Zienkiewicz scholarship awarded by Swansea University.

Author Contributions: Michael P. R. Sheldrick analysed the data and wrote the manuscript. Richard Tyler collected the data, assembled the input data and edited the manuscript. Gareth Stratton and Kelly A. Mackintosh supervised the analyses and edited the manuscript.

Conflicts of Interest: The authors declare no conflict of interest. 


\section{References}

1. Karnik, S.; Kanekar, A.A. Childhood Obesity: A Global Public Health Crisis. Int. J. Prev. Med. 2012, 1, 1-7. [CrossRef]

2. Jones, M.; Blackaby, D.; Murphy, P. Childhood Obesity in Wales. Welsh Econ. Rev. 2006, 22, $36-42$.

3. Singh, A.S.; Mulder, C.; Twisk, J.W.R.; Van Mechelen, W.; Chinapaw, M.J.M. Tracking of childhood overweight into adulthood: A systematic review of the literature. Obes. Rev. 2008, 9, 474-488. [CrossRef] [PubMed]

4. Bridger, T. Childhood obesity and cardiovascular disease. Paediatr. Child Health 2009, 14, 177-182. [CrossRef] [PubMed]

5. Pulgaron, E.R.; Delamater, A.M. Obesity and type 2 diabetes in children: Epidemiology and treatment. Curr. Diab. Rep. 2014, 14, 1-21. [CrossRef] [PubMed]

6. Biro, F.M.; Wien, M. Childhood obesity and adult morbidities. Am. J. Clin. Nutr. 2010, 91, 1499-1505. [CrossRef]

7. Poitras, V.J.; Gray, C.E.; Borghese, M.M.; Carson, V.; Chaput, J.; Janssen, I.; Katzmarzyk, P.T.; Pate, R.R.; Gorber, S.C.; Kho, M.E.; et al. Systematic review of the relationships between objectively measured physical activity and health indicators in school-aged children and youth. Appl. Physiol. Nutr. Metab. 2016, 239. [CrossRef] [PubMed]

8. Bhadoria, A.; Sahoo, K.; Sahoo, B.; Choudhury, A.; Sufi, N.; Kumar, R. Childhood obesity: Causes and consequences. J. Fam. Med. Prim. Care 2015, 4, 187. [CrossRef] [PubMed]

9. Carson, V.; Tremblay, M.S.; Chaput, J.-P.; Chastin, S.F.; Carson, V.; Tremblay, M.; Chaput, J.; Chastin, S. Associations between sleep duration, sedentary time, physical activity, and health indicators among Canadian children and youth using compositional analyses 1. Appl. Physiol. Nutr. Metab. 2016, 41, 294-302. [CrossRef] [PubMed]

10. Carson, V.; Hunter, S.; Kuzik, N.; Gray, C.E.; Poitras, V.J.; Chaput, J.-P.; Saunders, T.J.; Katzmarzyk, P.T.; Okely, A.D.; Connor Gorber, S.; et al. Systematic review of sedentary behaviour and health indicators in school-aged children and youth: An update 1. Appl. Physiol. Nutr. Metab. 2016, 41, 240-265. [CrossRef] [PubMed]

11. Ledoux, T.A.; Hingle, M.D.; Baranowski, T. Relationship of fruit and vegetable intake with adiposity: A systematic review. Obes. Rev. 2011, 12, 143-150. [CrossRef] [PubMed]

12. Wilkie, H.J.; Standage, M.; Gillison, F.B.; Cumming, S.P.; Katzmarzyk, P.T. Multiple lifestyle behaviours and overweight and obesity among children aged 9-11 years: Results from the UK site of the International Study of Childhood Obesity, Lifestyle and the Environment. BMJ Open 2016, 6, e010677. [CrossRef] [PubMed]

13. Katzmarzyk, P.T.; Barreira, T.V.; Broyles, S.T.; Champagne, C.M.; Chaput, J.P.; Fogelholm, M.; Hu, G.; Johnson, W.D.; Kuriyan, R.; Kurpad, A.; et al. Physical Activity, Sedentary Time, and Obesity in an International Sample of Children. Med. Sci. Sports Exerc. 2015, 47, 2062-2069. [CrossRef] [PubMed]

14. Stone, M.R.; Stevens, D.; Faulkner, G.E.J. Maintaining recommended sleep throughout the week is associated with increased physical activity in children. Prev. Med. 2013, 56, 112-117. [CrossRef] [PubMed]

15. Lazzeri, G.; Azzolini, E.; Pammolli, A.; De Wet, D.R.; Giacchi, M.V. Correlation between physical activity and sedentary behavior with healthy and unhealthy behaviors in Italy and Tuscan region: A cross sectional study. J. Prev. Med. Hyg. 2013, 54, 41-48. [PubMed]

16. Silva, D.A.S.; Silva, R.J.D.S. Association between physical activity level and consumption of fruit and vegetables among adolescents in northeast Brazil. Rev. Paul. Pediatr. 2015, 33, 167-173. [CrossRef] [PubMed]

17. Pearson, N.; Atkin, A.J.; Biddle, S.J.; Gorely, T.; Edwardson, C. Patterns of adolescent physical activity and dietary behaviours. Int. J. Behav. Nutr. Phys. Act. 2009, 6, 45. [CrossRef] [PubMed]

18. Szczerbiński, R.; Karczewski, J.K.; Siemienkowicz, J. Selected Nourishment Habits Depending on Physical Activity of 14-16 Year-Old Teenagers in the North-Eastern Poland on the Example of Sokolski District. Rocz. Panstw. Zaki. Hig. 2010, 61, 83-86.

19. Booth, J.N.; Leary, S.D.; Joinson, C.; Ness, A.R.; Tomporowski, P.D.; Boyle, J.M.; Reilly, J.J. Associations between objectively measured physical activity and academic attainment in adolescents from a UK cohort. Br. J. Sports Med. 2014, 48, 265-270. [CrossRef] [PubMed]

20. Sjödin, A.; Hjorth, M.F.; Damsgaard, C.T.; Ritz, C.; Astrup, A.; Michaelsen, K.F. Physical activity, sleep duration and metabolic health in children fluctuate with the lunar cycle: Science behind the myth. Clin. Obes. 2015, 5, 60-66. [CrossRef] [PubMed] 
21. Mcneil, J.; Tremblay, M.S.; Leduc, G.; Boyer, C.; Bélanger, P.; Leblanc, A.G.; Borghese, M.M.; Chaput, J.P. Objectively-measured sleep and its association with adiposity and physical activity in a sample of Canadian children. J. Sleep Res. 2015, 24, 131-139. [CrossRef] [PubMed]

22. Vaisto, J.; Eloranta, A.M.; Viitasalo, A.; Tompuri, T.; Lintu, N.; Karjalainen, P.; Lampinen, E.K.; Agren, J.; Laaksonen, D.E.; Lakka, H.M.; et al. Physical activity and sedentary behaviour in relation to cardiometabolic risk in children: Cross-sectional findings from the Physical Activity and Nutrition in Children (PANIC) Study. Int. J. Behav. Nutr. Phys. Act. 2014, 11, 55. [CrossRef] [PubMed]

23. Department of Health, Physical Activity, Health Improvement and Protection. Start Active, Stay Active: A Report on Physical Activity for Health from the Four Home Countries' Chief Medical Officers; Crown: London, UK, 2011.

24. Atkin, A.J.; Gorely, T.; Biddle, S.J.H.; Marshall, S.J.; Cameron, N. Critical hours: Physical activity and sedentary behavior of adolescents after school. Pediatr. Exerc. Sci. 2008, 20, 446-456. [CrossRef] [PubMed]

25. Hale, L.; Guan, S. Screen time and sleep among school-aged children and adolescents: A systematic literature review. Sleep Med. Rev. 2015, 21, 50-58. [CrossRef] [PubMed]

26. Falbe, J.; Davison, K.K.; Franckle, R.L.; Ganter, C.; Gortmaker, S.L.; Smith, L.; Land, T.; Taveras, E.M. Sleep Duration, Restfulness, and Screens in the Sleep Environment. Pediatrics 2015, 135, e367-e375. [CrossRef] [PubMed]

27. Olds, T.; Maher, C.A.; Ridley, K. The Place of Physical Activity in the Time Budgets of 10-to 13-Year-Old Australian Children. J. Phys. Act. Health 2011, 8, 548-557. [CrossRef] [PubMed]

28. Shang, L.; Wang, J.W.; O’Loughlin, J.; Tremblay, A.; Mathieu, M.È.; Henderson, M.; Gray-Donald, K. Screen time is associated with dietary intake in overweight Canadian children. Prev. Med. Rep. 2015, 2, 265-269. [CrossRef] [PubMed]

29. Börnhorst, C.; Wijnhoven, T.M.A.; Kunešová, M.; Yngve, A.; Rito, A.I.; Lissner, L.; Duleva, V.; Petrauskiene, A.; Breda, J. WHO European Childhood Obesity Surveillance Initiative: Associations between sleep duration, screen time and food consumption frequencies. BMC Public Health 2015, 15, 442. [CrossRef] [PubMed]

30. Hare-Bruun, H.; Nielsen, B.M.; Kristensen, P.L.; Møller, N.C.; Togo, P.; Heitmann, B.L. Television viewing, food preferences, and food habits among children: A prospective epidemiological study. BMC Public Health 2011, 11, 311. [CrossRef] [PubMed]

31. Saunders, T.J.; Chaput, J.P.; Tremblay, M.S. Sedentary behaviour as an emerging risk factor for cardiometabolic diseases in children and youth. Can. J. Diabetes 2014, 38, 53-61. [CrossRef] [PubMed]

32. Tremblay, M.S.; Carson, V.; Chaput, J.-P.; Connor Gorber, S.; Dinh, T.; Duggan, M.; Faulkner, G.; Gray, C.E.; Gruber, R.; Janson, K.; et al. Canadian 24-Hour Movement Guidelines for Children and Youth: An Integration of Physical Activity, Sedentary Behaviour, and Sleep. Appl. Physiol. Nutr. Metab. 2016, 41, S311-S327. [CrossRef] [PubMed]

33. LeBlanc, A.G.; Katzmarzyk, P.T.; Barreira, T.V.; Broyles, S.T.; Chaput, J.P.; Church, T.S.; Fogelholm, M.; Harrington, D.M.; Hu, G.; Kuriyan, R.; et al. Correlates of total sedentary time and screen time in 9-11 year-old children around the world: The international study of childhood obesity, lifestyle and the environment. PLoS ONE 2015, 10, 1-20. [CrossRef] [PubMed]

34. Pearson, N.; Biddle, S.J.H.; Williams, L.; Worsley, A.; Crawford, D.; Ball, K. Adolescent television viewing and unhealthy snack food consumption: The mediating role of home availability of unhealthy snack foods. Public Health Nutr. 2014, 17, 317-323. [CrossRef] [PubMed]

35. Mota, J.; Ribeiro, J.C.; Carvalho, J.; Santos, M.P.; Martins, J. Television viewing and changes in body mass index and cardiorespiratory fitness over a two-year period in school children. Pediatr. Exerc. Sci. 2010, 22, 245-253. [CrossRef] [PubMed]

36. Fairclough, S.J.; Beighle, A.; Erwin, H.; Ridgers, N.D. School day segmented physical activity patterns of high and low active children. BMC Public Health 2012, 12, 406. [CrossRef] [PubMed]

37. Stratton, G.; Canoy, D.; Boddy, L.M.; Taylor, S.R.; Hackett, A.F.; Buchan, I.E. Cardiorespiratory fitness and body mass index of 9-11-year-old English children: A serial cross-sectional study from 1998 to 2004. Int. J. Obes. 2007, 31, 1172-1178. [CrossRef] [PubMed]

38. Noble, M.; Wright, G.; Smith, G.; Dibben, C. Measuring multiple deprivation at the small-area level. Environ. Plan. A 2006, 38, 169-185. [CrossRef]

39. Lohman, T.G.; Roche, A.F.; Martorell, R. Anthropometric Standardization Reference Manual; Wiley: New York, NY, USA, 1992. [CrossRef] 
40. Cole, T.J. Growth monitoring with the British 1990 growth reference. Arch. Dis. Child. 1997, 76, 47-49. [CrossRef] [PubMed]

41. Léger, L.A.; Mercier, D.; Gadoury, C.; Lambert, J. The multistage 20 metre shuttle run test for aerobic fitness. J. Sports Sci. 1988, 6, 93-101. [CrossRef] [PubMed]

42. Mayorga-vega, D.; Aguilar-soto, P.; Viciana, J. Criterion-Related Validity of the 20-M Shuttle Run Test for Estimating Cardiorespiratory Fitness: A Meta-Analysis. J. Sports Sci. Med. 2015, 14, 536-547. [PubMed]

43. Riddoch, C.J. The Northern Ireland Health and Fitness Survey-1989: The Fitness, Physical Activity, Attitudes and Lifestyles of Northern Ireland Post-Primary School Children; The Queen's University of Belfast: Belfast, UK, 1990.

44. Fairclough, S.J.; Boddy, L.M.; Hackett, A.F.; Stratton, G. Associations between children's socioeconomic status, weight status, and sex, with screen-based sedentary behaviours and sport participation. Int. J. Pediatr. Obes. 2009, 4, 299-305. [CrossRef] [PubMed]

45. Lumley, T.; Diehr, P.; Emerson, S.; Chen, L. The Importance of the Normality Assumption in Large Public Health Data Sets. Annu. Rev. Public Health 2002, 23, 151-169. [CrossRef] [PubMed]

46. Williams, M.; Grajales, C.A.G.; Kurkiewicz, D. Assumptions of multiple regression: Correcting two misconceptions. Pract. Assess. Res. Eval. 2013, 18, 1-14.

47. Pearson, N.; Braithwaite, R.E.; Biddle, S.J.H.; van Sluijs, E.M.F.; Atkin, A.J. Associations between sedentary behaviour and physical activity in children and adolescents: A meta-analysis. Obes. Rev. 2014, 15, 666-675. [CrossRef] [PubMed]

48. Sallis, J.; Prochaska, J.; Taylor, W. A review of correlates of physical activity. Med. Sci. Sport. Exerc. 2000, 32, 963-975. [CrossRef]

49. Pearson, N.; Biddle, S.J.H. Sedentary behavior and dietary intake in children, adolescents, and adults: A systematic review. Am. J. Prev. Med. 2011, 41, 178-188. [CrossRef] [PubMed]

50. Ottevaere, C.; Huybrechts, I.; Béghin, L.; Cuenca-Garcia, M.; de Bourdeaudhuij, I.; Gottrand, F.; Hagströmer, M.; Kafatos, A.; Le Donne, C.; Moreno, L.A.; et al. Relationship between self-reported dietary intake and physical activity levels among adolescents: The HELENA study. Int. J. Behav. Nutr. Phys. Act. 2011, 8, 8. [CrossRef] [PubMed]

51. Pereira, S.; Katzmarzyk, P.T.; Gomes, T.N.; Borges, A.; Santos, D.; Souza, M.; dos Santos, F.K.; Chaves, R.N.; Champagne, C.M.; Barreira, T.V.; et al. Profiling physical activity, diet, screen and sleep habits in Portuguese children. Nutrients 2015, 7, 4345-4362. [CrossRef] [PubMed]

52. Vissers, P.A.J.; Jones, A.P.; van Sluijs, E.M.F.; Jennings, A.; Welch, A.; Cassidy, A.; Griffin, S.J. Association between diet and physical activity and sedentary behaviours in 9-10-year-old British White children. Public Health 2012, 127, 231-240. [CrossRef] [PubMed]

53. Jago, R; Ness, A.R; Emment, P.; Mattocks, C.; Jones, L.; Riddoch, C.J. Obesogenic diet and physical activity behaviours: Independent or associated behaviours in adolescents. Public Health Nutr. 2010, 13, 673-681. [CrossRef] [PubMed]

54. Nelson, T.D.; Lundahl, A.; Molfese, D.L.; Waford, R.N.; Roman, A.; Gozal, D.; Molfese, V.J.; Ferguson, M.C. Estimating child sleep from parent report of time in bed: Development and evaluation of adjustment approaches. J. Pediatr. Psychol. 2014, 39, 624-632. [CrossRef] [PubMed]

55. Short, M.A.; Gradisar, M.; Lack, L.C.; Wright, H.R.; Chatburn, A. Estimating adolescent sleep patterns: Parent reports versus adolescent self-report surveys, sleep diaries, and actigraphy. Nat. Sci. Sleep 2013, 5, $23-26$. [CrossRef] [PubMed]

56. Yamakita, M.; Sato, M.; Ando, D.; Suzuki, K.; Yamagata, Z. Availability of a simple self-report sleep questionnaire for 9- to 12-year-old children Study participants. Sleep Biol. Rhythms 2014, 12, 279-288. [CrossRef]

57. Ekstedt, M.; Nyberg, G.; Ingre, M.; Ekblom, Ö.; Marcus, C. Sleep, physical activity and BMI in six to tenyear-old children measured by accelerometry: A cross-sectional study. Int. J. Behav. Nutr. Phys. Act. 2013, 10, 1. [CrossRef] [PubMed]

58. Khan, M.K.A.; Chu, Y.L.; Kirk, S.F.L.; Veugelers, P.J. Are sleep duration and sleep quality associated with diet quality, physical activity, and body weight status? A population-based study of Canadian children. Can. J. Public Health 2015, 106, e277-e282. [CrossRef] [PubMed]

59. Jimenez-Pavon, D.; Kelly, J.; Reilly, J.J. Associations between objectively measured habitual physical activity and adiposity in children and adolescents: Systematic review. Int. J. Pediatr. Obes. 2010, 5, 3-18. [CrossRef] [PubMed] 
60. Parikh, T.; Stratton, G. Influence of intensity of physical activity on adiposity and cardiorespiratory fitness in 518 year olds. Sports Med. 2011, 41, 477-488. [CrossRef] [PubMed]

61. Roman-Viñas, B.; Chaput, J.-P.; Katzmarzyk, P.T.; Fogelholm, M.; Lambert, E.V.; Maher, C.; Maia, J.; Olds, T.; Onywera, V.; Sarmiento, O.L.; et al. Proportion of children meeting recommendations for 24-hour movement guidelines and associations with adiposity in a 12-country study. Int. J. Behav. Nutr. Phys. Act. 2016, $13,123$. [CrossRef] [PubMed]

62. Kelly, B.; Halford, J.C.G.; Boyland, E.J.; Chapman, K.; Bautista-Castaño, I.; Berg, C.; Caroli, M.; Cook, B.; Coutinho, J.G.; Effertz, T.; et al. Television food advertising to children: A global perspective. Am. J. Public Health 2010, 100, 1730-1736. [CrossRef] [PubMed]

63. Boyland, E.J.; Halford, J.C.G. Television advertising and branding. Effects on eating behaviour and food preferences in children. Appetite 2013, 62, 236-241. [CrossRef] [PubMed]

64. Hysing, M.; Pallesen, S.; Stormark, K.M.; Jakobsen, R.; Lundervold, A.J.; Sivertsen, B. Sleep and use of electronic devices in adolescence: Results from a large population-based study. BMJ Open 2015, 5, e006748. [CrossRef] [PubMed]

65. Marques, A.; Ekelund, U.; Sardinha, L.B. Associations between organized sports participation and objectively measured physical activity, sedentary time and weight status in youth. J. Sci. Med. Sport 2015, 19, 1-4. [CrossRef] [PubMed]

66. Morgan, K.; Hallingberg, B.; Littlecott, H.; Murphy, S.; Fletcher, A.; Roberts, C.; Moore, G. Predictors of physical activity and sedentary behaviours among 11-16 year olds: Multilevel analysis of the 2013 Health Behaviour in School-aged Children (HBSC) study in Wales. BMC Public Health 2016, 16, 569. [CrossRef] [PubMed]

67. Hatch, K.E. Determining the Effects of Technology on Children. 2011. Available online: http:// digitalcommons.uri.edu/srhonorsprog/260/ (access on 14 February 2018).

68. Gorely, T.; Biddle, S.; Marshall, S.; Cameron, N.; Cassey, N. The association between distance to school, physical activity and sedentary behaviors in adolescents: Project STIL. Pediatr. Exerc. Sci. 2009, 21, 450-461. [CrossRef] [PubMed]

69. Arundell, L.; Hinkley, T.; Veitch, J.; Salmon, J. Contribution of the after-school period to children's daily participation in physical activity and sedentary behaviours. PLOS ONE 2015, 10, 1-11. [CrossRef] [PubMed]

70. Ar-Yuwat, S.; Clark, M.J.; Hunter, A.; James, K.S. Determinants of physical activity in primary school students using the health belief model. J. Multidiscip. Healthc. 2013, 6, 119-126. [CrossRef] [PubMed]

71. Feldman, D.E.; Barnett, T.; Shrier, I.; Rossignol, M.; Abenhaim, L. Is physical activity differentially associated with different types of sedentary pursuits? Arch. Pediatr. Adolesc. Med. 2003, 157, 797-802. [CrossRef] [PubMed]

72. Jago, R.; Sebire, S.J.; Gorely, T.; Cillero, I.H.; Biddle, S.J.H. " I'm on it 24/7 at the moment ": A qualitative examination of multi-screen viewing behaviours among UK 10-11 year olds. Int. J. Behav. Nutr. Phys. Act. 2011, 1-8. [CrossRef] [PubMed]

73. Pate, R.R.; Taverno Ross, S.E.; Liese, A.D.; Dowda, M. Associations among physical activity, diet quality, and weight status in US adults. Med. Sci. Sports Exerc. 2015, 47, 743-750. [CrossRef] [PubMed]

74. Fortes, L.; Morgado, F.; Almeida, S.; Ferreira, M. Eating behavior and physical activity in adolescents. Rev. Nutr. 2013, 26, 529-537. [CrossRef]

75. Atkin, A.J.; Gorely, T.; Clemes, S.A.; Yates, T.; Edwardson, C.; Brage, S.; Salmon, J.; Marshall, S.J.; Biddle, S.J.H. Methods of measurement in epidemiology: Sedentary behaviour. Int. J. Epidemiol. 2012, 41, 1460-1471. [CrossRef] [PubMed]

76. Hjorth, M.F.; Chaput, J.P.; Damsgaard, C.T.; Dalskov, S.M.; Andersen, R.; Astrup, A.; Michaelsen, K.F.; Tetens, I.; Ritz, C.; Sjödin, A. Low physical activity level and short sleep duration are associated with an increased cardio-metabolic risk profile: A longitudinal study in 8-11 year old Danish children. PLoS ONE 2014, 9. [CrossRef] [PubMed]

77. Wang, L.; Luo, J.; Luo, J.; Gao, W.; Kong, J. The effect of Internet use on adolescents' lifestyles: A national survey. Comput. Human Behav. 2012, 28, 2007-2013. [CrossRef]

78. Gordon-Larsen, P.; Adair, L.S.; Popkin, B.M. Ethnic differences in physical activity and inactivity patterns and overweight status. Obes. Res. 2002, 10, 141-149. [CrossRef] [PubMed] 
79. Elsenburg, L.K.; Corpeleijn, E.; van Sluijs, E.M.F.; Atkin, A.J. Clustering and correlates of multiple health behaviours in 9-10 year old children. PLoS ONE 2014, 9, e99498. [CrossRef] [PubMed]

80. Maitland, C.; Stratton, G.; Foster, S.; Braham, R.; Rosenberg, M. A place for play? The influence of the home physical environment on children's physical activity and sedentary behaviour. Int. J. Behav. Nutr. Phys. Act. 2013, 10, 1. [CrossRef] [PubMed] 